\title{
Sulfatase-2: a prognostic biomarker and candidate therapeutic target in patients with pancreatic ductal adenocarcinoma
}

\author{
Sari F Alhasan ${ }^{1,6}$, Beate Haugk ${ }^{2,6}$, Laura F Ogle ${ }^{1}$, Gary S Beale ${ }^{1}$, Anna Long ${ }^{2}$, Alastair D Burt ${ }^{2,3}$, \\ Dina Tiniakos ${ }^{2,4}$, Despina Televantou ${ }^{1,2}$, Fareeda Coxon ${ }^{5}$, David R Newell ${ }^{1}$, Richard Charnley ${ }^{5}$ and \\ Helen L Reeves ${ }^{\star}, 1,5$ \\ ${ }^{1}$ Northern Institute for Cancer Research, Paul O'Gorman Building, The Medical School, Framlington Place, Newcastle University, \\ Newcastle upon Tyne NE2 4HH, UK; ${ }^{2}$ Department of Cellular Pathology, Royal Victoria Infirmary, Newcastle upon Tyne Hospitals \\ NHS Foundation Trust, Newcastle upon Tyne NE1 4LP, UK; ${ }^{3}$ School of Medicine, Eleanor Harrald Building, Frome Road, \\ The University of Adelaide, Adelaide, 5000 South Australia, Australia; ${ }^{4}$ Institute of Cellular Medicine, The Medical School, \\ Framlington Place, Newcastle University, Newcastle upon Tyne NE2 4HH, UK and ${ }^{5}$ Hepatopancreatobiliary multidisciplinary team, \\ Freeman Hospital, Newcastle-upon-Tyne Hospitals NHS Foundation Trust, Newcastle upon Tyne NE7 7DN, UK
}

Background: Pancreatic ductal adenocarcinoma (PDAC) is the fifth most common cause of cancer death in the UK. Its poor prognosis is attributed to late detection and limited therapeutic options. Expression of SULF2, an endosulfatase that modulates heparan sulfate proteoglycan 6-O-sulfation and is reportedly tumourigenic in different types of cancer, was investigated.

Methods: SULF2 expression was determined immunohistochemically in archival surgical resection tissue sections from 93 patients with a confirmed histological diagnosis of PDAC between 2002 and 2008 followed for a median of 9 years. Relationships with clinico-pathological parameters and patient survival were explored.

Results: The majority of PDACs showed positive SULF2 staining in tumour cells and intratumoural or tumour-adjacent stroma. Greater than 25\% SULF2-positive tumour cells was present in 60\% of cancers and correlated with tumour stage $(P=0.002)$ and perineural invasion $(P=0.024)$. SULF2 intensity was scored moderate or strong in $81 \%$ of cancers and positively correlated with vascular invasion $(P=0.015)$. High SULF2 expression, defined as $>50 \%$ SULF2-positive tumour cells and strong SULF2 staining, was associated with shorter time to radiological progression $(P=0.018, H R 1.98, C l 1.13-3.47)$. Similarly, by multivariate analysis, high SULF2 expression was independently associated with poorer survival $(P=0.004, \mathrm{HR} 2.10, \mathrm{Cl} 1.26-3.54)$, with a median survival of 11 months vs 21 months for lower PDAC SULF2.

Conclusions: Elevated SULF2 in PDAC was associated with advanced tumour stage, vascular invasion, shorter interval to radiological progression and shorter overall survival. SULF2 may have roles as a prognostic biomarker and as a therapeutic target for patients with PDAC.

Each year, $\sim 8800$ people are diagnosed with pancreatic ductal adenocarcinoma (PDAC) in the UK (Cancer Research UK (Cancer Statistics)). A significant proportion of cancer-related death is attributed to PDAC (Siegel et al, 2012) with a 5-year survival rate in the region of $6 \%$ (DeSantis et al, 2014). PDAC is asymptomatic in early stages and its poor prognosis is attributed to late detection,

\footnotetext{
${ }^{\star}$ Correspondence: Dr HL Reeves; E-mail: helen.reeves@ncl.ac.uk

${ }^{6}$ These two authors contributed equally to this work.
} 
as well as the aggressive nature of the disease (Chrystoja et al, 2013). Consequently, only $10-15 \%$ of those affected are candidates for surgical resection, with a 5-year survival post resection of just $10-25 \%$ owing to frequent regional invasion and distant micrometastases at the time of resection (Heinemann and Boeck, 2008). The current palliative chemotherapy regimens for those with later stage disease include gemcitabine with or without nab-paclitaxel, or FOLFIRINOX and provide modest benefit with a median overall survival of $<1$ year (Conroy et al, 2011; Thota et al, 2014).

Clinically useful biomarkers which inform prognosis or aid treatment stratification for those with PDAC are presently lacking. The contribution of extracellular microenvironment (ECM) to the development and progression of PDAC is recognised (Apte et al, 2015), as is a role for the pro-angiogenic vascular endothelial growth factor (VEGF), which is expressed in $>90 \%$ of cases, and associated with both liver metastases and shorter survival of patients (Seo et al, 2000). ECM interactions with angiogenic as well as proliferative signalling pathways are closely regulated by heparan sulfate proteoglycans (HSPGs). VEGF is one of the HSPG-bound proteins, which include other ligands relevant to PDAC progression such as FGF-1 and FGF-2, Wnts and ECM components such as collagens, fibronectin and laminin which are present in PDAC stroma. The heparan sulfate (HS) chains of HSPGs are rich in uronic acid moieties and sulfate groups that are negatively charged, producing binding sites for growth factors, receptors and ECM molecules. Charge, and therefore sequestration $v s$ release of growth factors, as well as orientation and binding affinity, are regulated by the degree of sulfation - particularly at the 6-O position of HS chains (Pye et al, 1998, 2000; Ai et al, 2003). 6 -O-Sulfation is in turn regulated by sulfotransferases which add sulfate groups and the extracellular endosulfatases, sulfatase-1 (SULF1) and sulfatase-2 (SULF2), which remove them (MorimotoTomita et al, 2002; Saad et al, 2005; Staples et al, 2011).

SULF2 has been reported to be upregulated and to have a candidate oncogenic role in a number of cancers, including glioblastoma, liver, lung, gastric, oesophageal and prostate cancers (Hur et al, 2012; Lai et al, 2008, 2010; Lemjabbar-Alaoui et al, 2010; Lui et al, 2012; Phillips et al, 2012). In PDAC, Nawroth et al (2007) have previously reported an increase in SULF2 mRNA in cell lines and increased SULF2 protein expression relative to non-tumour tissues expression in a small number of cases. shRNA-mediated SULF2 knockdown or transfection with a catalytically inactive dominant form of SULF2 enzyme in 3 PDAC cell lines reduced cell growth in vitro and tumourigenicity in vivo (Nawroth et al, 2007).

In this study, we have assessed SULF2 as a candidate immunohistochemical prognostic biomarker in a cohort of 93 patients who underwent PDAC resection. In the majority of cases SULF2 was overexpressed in PDAC cells, with the percentage of positive cells correlating with tumour stage, and the SULF2 intensity (SI) correlating with vascular invasion. Combining percentage of positive cells and SI, high-PDAC SULF2 was associated with vascular invasion, a shorter time to radiological progression and poorer overall survival.

\section{MATERIALS AND METHODS}

Patient cohort. As part of a pilot study, SULF2 expression was assessed in formalin-fixed paraffin-embedded tissues (FFPE) from 19 patients undergoing resection for PDAC and consenting to the use of their tissues for research projects, governed by the Newcastle upon Tyne Hepatopancreatobiliary Research Tissue bank. The data presented include these cases, in combination with data generated subsequently from a larger retrospective series (an additional 74 cases), exploring SULF2 expression in archived cases from patients with a confirmed histological diagnosis PDAC. Study of the retrospective case series was approved by the Newcastle and North Tyneside Regional ethics committee (REC approval 11/H0908/02) on 03 March 2011. The selection interval was from 2002 to 2008 and the REC waived the need for informed consent. Patient confidentiality was respected at all times and analyses were on code-linked anonymised data sets. The Newcastle upon Tyne NHS Foundation Trust Research and Development department approved this project.

The study is classed as a retrospective case series, including patients undergoing resection with curative intent, in whom a diagnosis of PDAC was histologically confirmed. Additional inclusion criteria included the availability of FFPE blocks for study. Patients with known distant metastases at the time of resection were excluded, as were those with histologically benign disease or cholangiocarcinoma.

Clinico-pathological information, including Union for International Cancer Control tumour node metastases (TNM) stage, tumour grade, vascular, lymphatic and perineural invasion, lymph node status, resection margin status, time to progression (TTP) and patient survival, was collected from histopathology reports, radiology reports and patient records. Patient demographics and clinico-pathological data are shown in Table 1. The patients were followed-up for a median of 9.4 (range 6.1 to 12.9) years until 31 December 2014.

Immunohistochemistry. SULF2 immunohistochemistry was performed on a Benchmark Ultra autostainer (Ventana, Tucson, AZ, USA) using anti-SULF2 antibody (catalogue number MCA5692GA, AbD Serotec, Oxford, UK) at a dilution of 1:150. In brief, the tissue sections were incubated in primary antibody for 32 min following heat-induced epitope retrieval using CC1 buffer (Ventana) for $64 \mathrm{~min}$ at $100^{\circ} \mathrm{C}$. Detection and visualisation was achieved using an OptiView IHC DAB Detection Kit and 4 min of OptiView Amplification (Ventana). Control cases without primary antibody confirmed an absence of non-specific staining. Examples are included in Supplementary Figure 1.

Scoring method. An expert pancreatic pathologist (BH) blinded to patient outcome assessed the SULF2-immunostained slides at $\times 100$ magnification. The percentage of SULF2-positive carcinoma cells was semi-quantitatively assessed with a score from $0-4 \quad(0=$ no carcinoma cells positive, $1=1-25 \%$ carcinoma cells positive, $2=26-50 \%$ carcinoma cells positive, $3=51-75 \%$ carcinoma cells positive and $4=76-100 \%$ carcinoma cells positive). The SULF2-specific SI was assessed with a score from $0-3(0=$ no staining, $1=$ weak, $2=$ moderate, $3=$ strong $)$. Representative cases for each score are shown in Figure 1. If a range of SI was noted the predominant score was used. The semiquantitative score of SULF2-positive PDAC cells and the intensity score were added and a summative combined score (range 0-7) was created for each case. In addition, the extent of stromal staining within the tumour and outside the tumour was scored from 0 to $2(0=$ no staining, $1=$ focal staining, $2=$ extensive staining). Staining of benign and dysplastic epithelium or of tissues unrelated to the tumour was recorded. Presence of endothelial staining was recorded on all cases as an internal positive control. A second experienced pathologist (DT) also blinded to patient outcome, evaluated 10 random SULF2-immunostained slides ( $\sim 10 \%$ of cases). Inter-observer agreement assessed by the Kappa measure was very good for percentage of SULF2 ${ }^{+ \text {ve }}$ tumour cells (0.75) and perfect (kappa statistic 1) for SULF2 SI.

Statistical analysis. All statistical analyses were conducted using SPSS statistical package (IBM, version 22). Percentage of SULF2positive cells and SI were treated as ordinal categorical variables. To identify relationships between percentage of SULF2-positive cells or SI with clinico-pathological features, cross-tabulation and $\chi^{2}$-tests were performed. The Monte Carlo correction was applied 
to groups with fewer than 5 cases. To explore factors associated with TTP or survival, univariate Cox regression was conducted. Only significantly associated factors were then analysed using multivariate Cox regression. Median TTP and survival times were calculated using Kaplan-Meier survival analysis. Missing data were excluded from statistical studies. Where analyses were performed on $<93$ cases, (e.g. TTP) numbers in the analysis are stipulated in the text.

\section{RESULTS}

Demographic data for the case series studied. Details of the case series of 93 patients undergoing elective curative surgery for PDAC are summarised in Table 1 . The median age was 65 years and 53 were male. The vast majority (92/93) underwent a Whipples' pancreatoduodenectomy for tumours in the head or neck of the pancreas. In one case the tumour was in the body and a total pancreatectomy was performed. None of the patients received preoperative chemotherapy. The series did not include patients with known metastatic disease and 70/93 were classed as having TNM stage 3 disease. Similarly, 61/93 tumours were graded as poorly differentiated, with the majority having vascular, perineural or lymphatic invasion (Table 1). Forty-six patients (50\%) received adjuvant chemotherapy. The commonest adjuvant regime (36 patients) was fluorouracil (5FU) and folinic acid, either as the standard of care or as part of the ESPAC III trial. Similarly, six patients received adjuvant gemcitabine. One patient received the DNA methyl transferase inhibitor MG98, another received capecitabine, whereas in two patients, the adjuvant regime was not documented. Thirty two of 88 patients were documented as receiving palliative second-line chemotherapy, most often gemcitabine, whereas two patients entered clinical trials. As a number of patients follow-up palliative care was outside of our tertiary referral centre, TTP was recorded as first documented 'radiological' progression. Consequently the data set was skewed towards those patients fit enough to undergo active monitoring, with analyses on progression being limited to the 67 patients in whom this clearly defined end point was available. Survival data were available in all 93 patients.

Elevated SULF2 expression was common in PDAC and the percentage of cells positive correlated with tumour stage. SULF2 was consistently identified in endothelial cells and relatively weak expression also observed in benign atrophic ductal epithelium. Weak-to-moderately intense cytoplasmic staining was occasionally observed in dysplastic epithelial cells of PanINs, in islet and acinar cells, periductal glands and benign ductal epithelial cells. Examples of these are shown in Supplementary Figure 1, as is variable staining that was present in lymph node sinuses, adipocytes and inflammatory cells. In contrast, expression of SULF2 in PDAC was frequently of greater intensity (Figure 1). In the PDAC cells, SULF2 was observed in the cytoplasm with a granular quality. Focal membranous staining was identified in tumours with clear cell morphology. Sixty per cent (56 out of 93) of PDACs contained $>25 \%$ of cells positively stained for SULF2. A summary of the immunohistochemical results is shown in Table 1.

The percentage of SULF2-positive tumour cells correlated significantly with tumour stage $(P=0.002)$, the majority (16 out of $22 ; 73 \%$ ) of cases with $>75 \%$ tumour cells positive being stage T3, with local invasion. The percentage of SULF2-positive PDAC cells also correlated with perineural invasion $(P=0.024)$.

Cytoplasmic SULF2 expression in intratumoural stromal fibroblasts was either focal or marked in 69\% (64 out of 93) of PDAC. SULF2 was also evaluated in the stroma outside the tumours and similarly showed either focal or marked staining in
Table 1. Clinico-pathological variables and SULF2 scores in patients with PDAC

\begin{tabular}{|c|c|}
\hline Patient characteristics & Number \\
\hline Total & 93 \\
\hline Age (years, median) & 65.3 \\
\hline Sex (female:male) & $40: 53$ \\
\hline $\begin{array}{l}\text { Tumour stage } \\
\text { T1: tumour within pancreas }<2 \mathrm{~cm} \\
\text { T2: tumour within pancreas }>2 \mathrm{~cm} \\
\text { T3: local invasion } \\
\text { T4: distant or large vessel invasion } \\
\text { Resection (R0:R1) } \\
\text { Lymph nodes (-ve: }+ \text { ve) }\end{array}$ & $\begin{array}{c}3 \\
19 \\
70 \\
1 \\
28: 65 \\
8: 85\end{array}$ \\
\hline $\begin{array}{l}\text { Tumour grade } \\
\text { Well differentiated } \\
\text { Moderately differentiated } \\
\text { Poorly differentiated } \\
\text { Vascular invasion (no:yes) } \\
\text { Perineural invasion (no:yes) } \\
\text { Lymphatic invasion (no:yes) } \\
\text { Lymph nodes positive }\end{array}$ & $\begin{array}{c}1 \\
31 \\
61 \\
16: 77 \\
2: 91 \\
33: 60 \\
8: 85\end{array}$ \\
\hline $\begin{array}{l}\text { Tumour site } \\
\text { Head of pancreas/neck/uncinate } \\
\text { Neck and body }\end{array}$ & $\begin{array}{c}89 / 2 / 1 \\
1\end{array}$ \\
\hline $\begin{array}{l}\text { Adjuvant chemotherapy } \\
\text { None } \\
\text { 5FU regime } \\
\text { Gemcitabine } \\
\text { Other (defined in text) }\end{array}$ & $\begin{array}{r}47 \\
36 \\
6 \\
4\end{array}$ \\
\hline Palliative second-line chemotherapy & $32 / 56$ \\
\hline Survival (median months) & 16.5 \\
\hline \multicolumn{2}{|l|}{ SULF2 scoring } \\
\hline $\begin{array}{l}\text { Percentage SULF2-positive tumour cells } \\
\begin{aligned} 0 & =0 \% \\
1 & =1-25 \% \\
2 & =26-50 \% \\
3 & =51-75 \% \\
4 & =75-100 \%\end{aligned}\end{array}$ & $\begin{array}{r}3 \\
34 \\
17 \\
17 \\
22\end{array}$ \\
\hline $\begin{array}{l}\text { SULF2 staining intensity } \\
\begin{aligned} 0 & =\text { None } \\
1 & =\text { Weak } \\
2 & =\text { Moderate } \\
3 & =\text { Strong }\end{aligned}\end{array}$ & $\begin{array}{r}3 \\
15 \\
38 \\
37\end{array}$ \\
\hline $\begin{array}{l}\text { SULF2 combined score } \\
0 \\
1 \\
2 \\
3 \\
4 \\
5 \\
6 \\
7\end{array}$ & $\begin{array}{r}3 \\
0 \\
9 \\
8 \\
35 \\
13 \\
13 \\
12\end{array}$ \\
\hline $\begin{array}{l}\text { SULF2 tumour stroma } \\
\text { None } \\
\text { Focal } \\
\text { Marked }\end{array}$ & $\begin{array}{l}29 \\
54 \\
10\end{array}$ \\
\hline $\begin{array}{l}\text { SULF2 stroma outside } \\
\text { None } \\
\text { Focal } \\
\text { Marked }\end{array}$ & $\begin{array}{l}17 \\
48 \\
28\end{array}$ \\
\hline
\end{tabular}

Abbreviations: $\mathrm{R}=$ resection margins; $\mathrm{R} 0=$ negative resection margins; $\mathrm{R} 1=$ microscopic tumour infiltration (that is, tumour cells present within $1 \mathrm{~mm}$ of the resection margin); SULF=sulfatase.

the majority of cases (76 out of 93; 82\%). Stromal expression of SULF2 did not correlate with either PDAC grade or stage.

SULF2 intensity in PDAC was positively associated with the presence of vascular invasion. In all, $81 \%$ (75 out of 93) of cancers showed moderate or strong intensity of SULF2 expression. 

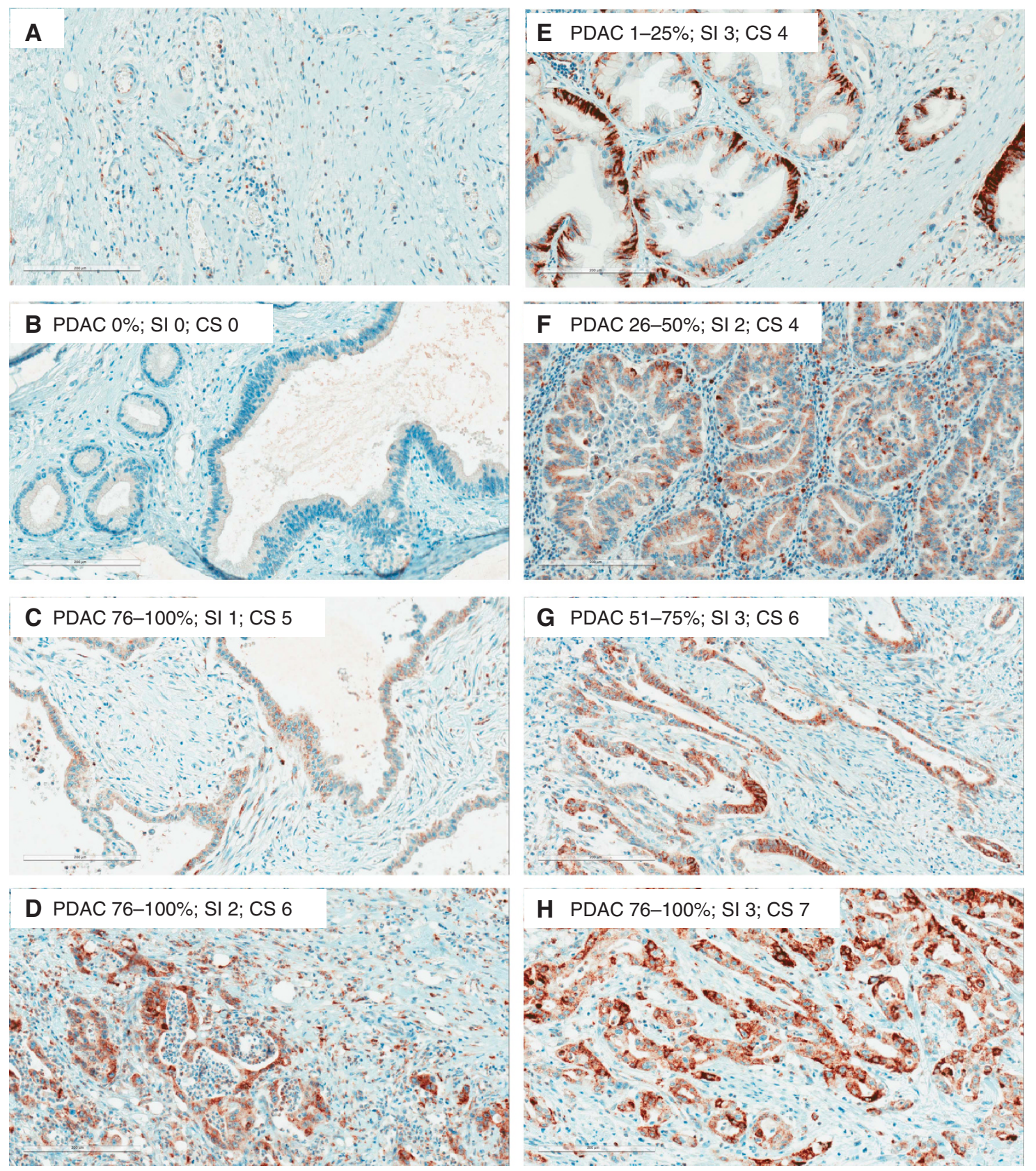

Figure 1. SULF2 expression in pancreatic ductal adenocarcinoma. Representative immunohistochemical images of PDAC cases showing different percentages of SULF2-positive tumour cells (0-100\%) and SI of SULF2 in tumour cells. SI 0: none, SI 1: weak, SI 2: moderate, SI 3: strong staining. (A) shows endothelial cell SULF2-positivity used as internal positive control. CS = combined SULF2 score.

The intensity correlated significantly with the presence of vascular invasion $(P=0.015)$.

The SULF2 combined score correlated with the presence of vascular invasion. The combined SULF2 IHC score of percentage cells positive and the level of intensity, as shown in Table 1, correlated significantly with the presence of vascular invasion $\left(P=0.026\right.$, Pearson's $\chi^{2}$, linear by linear association).

High-PDAC SULF2 was associated with a shorter time to radiological progression. Radiological TTP was documented in 67 out of 93 (62\%), with the median TTP being 11.6 months. One factor associated with radiological TTP was lymph node positivity $(P=0.007$, HR 4.15 , CI $1.49-11.58)$. Age, sex, tumour grade, tumour stage, resection margin status, vascular invasion, lymphatic invasion and perineural invasion had no significant impact on TTP in this relatively small series. Considering the SULF2 immunohistochemistry (IHC) scores applied, both ' $>75 \%$ PDAC cells SULF2 positive' or SULF2 SI scored as 'strong', were associated with significantly shorter TTP. Combining the IHC scores, as shown in Table 1, identified those cases with a combined score of 6 or 7 as having a poorer outcome. The median TTP was 8 months in this combined group, vs 13 months in combined groups scoring $0-5$, as shown in Supplementary Figure $2(P=0.018$, HR 1.98, CI 1.13-3.47). Both lymph node metastasis and the combined SULF2 score (groups $0-5$ vs 6-7), were independently associated with a shorter TTP (lymph nodes positive $P=0.006$, HR 4.28, CI 1.53-12; high SULF2 $P=0.014$, HR 2.05, CI 1.16-3.63, multivariate Cox regression; Supplementary Table 1).

Of the 67 cases with documented radiological TTP, 36 received adjuvant chemotherapy. Adjuvant chemotherapy had no significant impact on radiological TTP. Standard histopathological 
features were not associated with response to chemotherapy. However, the percentage of SULF2-positive PDAC cells trended towards significantly shorter TTP $(P=0.067$, HR 1.28 , CI 0.98-1.66), as did SI of PDAC cells $(P=0.062$, HR 1.58 , CI $0.98-2.54)$. High SULF2 using the combined IHC SULF2 score was associated with a median TTP of 10.8 months vs 15.5 months for those with lower SULF2 $(P=0.013$, HR 2.76, CI 1.24-6.17).

High-PDAC SULF2 was significantly associated with shorter overall survival. The overall mortality during the period of follow-up was $94 \%$ (87 out of 93 ), with a median of 16.5 months post resection until death (range $0.3-148$, s.d. 30). Factors significantly associated with survival post resection included age, lymph node metastasis and receipt of adjuvant chemotherapy, as assessed by univariate Cox regression analysis (Table 2). Regarding SULF2, those cases with $>75 \%$ of PDAC cells positive had a poorer outcome, as did those cases with strong SI compared with cases without SULF2 expression (Table 2). PDAC with a combined SULF2 score 6 or 7 had a significantly poorer overall survival (Table 2). Comparing combined groups $0-5$ vs 6-7, the median

Table 2. Factors associated with survival

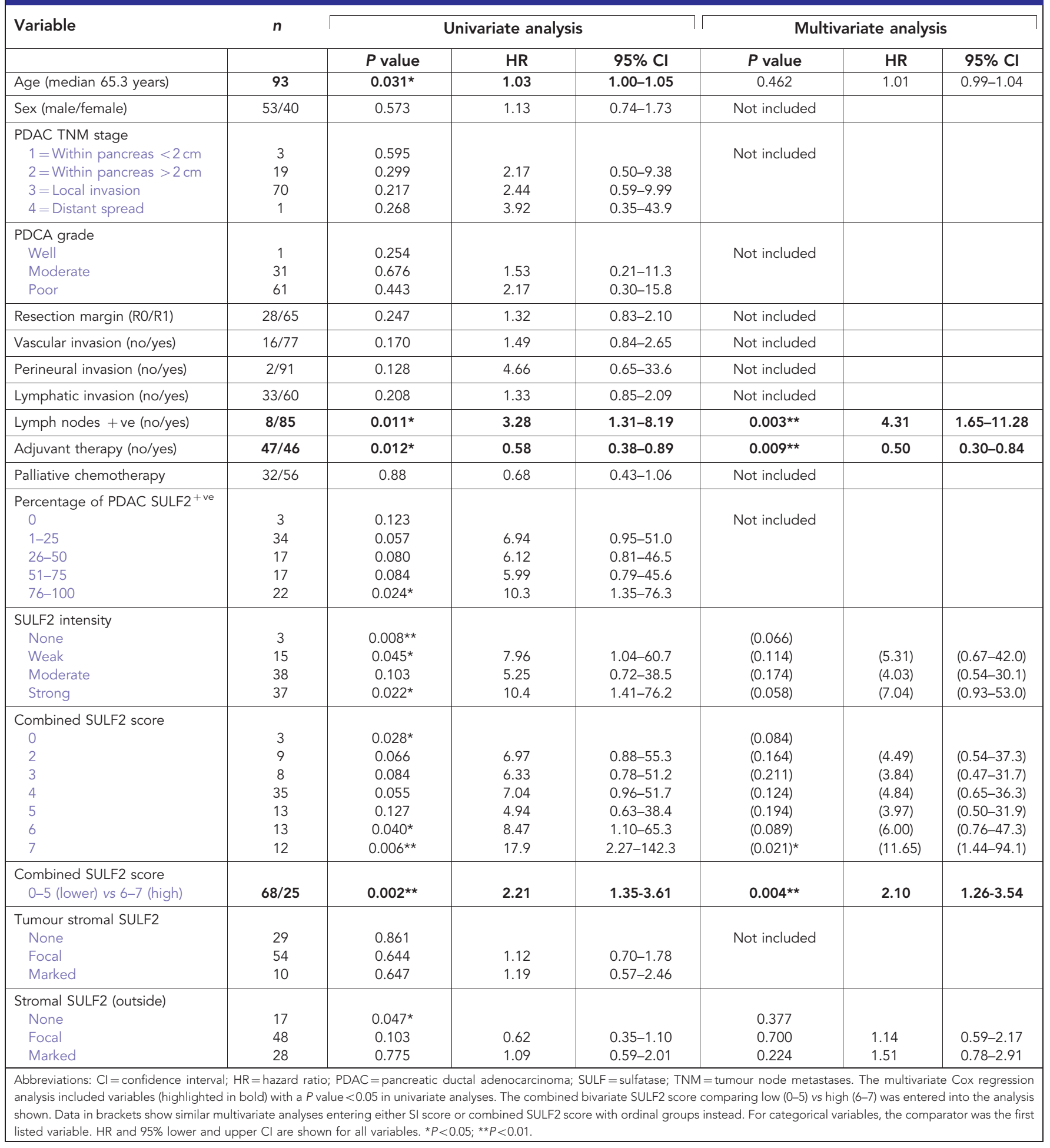


patient survival was 21 months vs 11 months, respectively $(P=0.002$, HR 2.21, CI $1.35-3.61)$, as shown in Figure 2A. Multivariate Cox regression analysis, including age, lymph node metastasis, receipt of adjuvant therapy, combined SULF2 IHC score $0-5$ vs 6-7 and stromal SULF2 outside the tumour is shown in Table 2. The presence of lymph node metastasis and high SULF2 expression were independently associated with a poorer survival, whereas receipt of adjuvant chemotherapy was associated with improved survival.

In the subgroup of patients who received adjuvant chemotherapy $(n=46)$, age, sex and tumour features had no impact on survival. Again, however, higher SULF2-positive PDAC cells or strong SULF2 SI were associated with poorer outcomes. Using the combined IHC score, median survival was 25 months in those with lower SULF2 (score 0-5) vs 12 months in those with a high SULF2 (score $6-7 ; P=0.001$, HR 3.23 , CI $1.59-6.57$ ) as shown in Figure 2B.

\section{DISCUSSION}

The development of personalised or precision medicine for cancer therapy requires the discovery, qualification and clinical use of prognostic and predictive biomarkers. In PDAC the most common driver genes with recurrent mutations; KRAS, SMAD4, TP53 and $C D K N 2 A / p 16$, cannot currently be exploited by available targeted therapies. Whole-genome sequencing has identified new candidates which may be druggable, but at low individual prevalence (Waddell et al, 2015). Hence predictive biomarkers that can be used to select specific treatments for individual patients have not had a major impact on the management of the disease, with systemic treatment being limited to single agent (e.g., gemcitabine) or combination (e.g., FOLFIRINOX) cytotoxic drug therapy.

The major focus for biomarker discovery in PDAC has therefore been the identification of novel prognostic biomarkers to inform clinical decision making. For example, to identify poor prognosis patients that might be suitable for experimental therapy in the primary setting, and those with a relatively favourable prognosis in whom more aggressive conventional treatments may be appropriate. A large number of conventional clinical, circulating and pathological factors (Giovinazzo et al, 2012; Winter et al, 2013; Bilici, 2014; Jazieh et al, 2014; Lamarca and Feliu, 2014), as well as genomic and proteomic parameters (Marengo and Robotti, 2014), have been the subject of biomarker discovery research in PDAC. However, the glycoprotein CA19-9, the only FDA approved biomarker for PDAC, is the sole factor in widespread routine clinical use. Serum CA19-9 has utility as a diagnostic, prognostic and surrogate response biomarker, but it has well known limitations and its precise value in these settings remains the subject of debate (Bilici, 2014; Jazieh et al, 2014).

Thus far, meta-analyses of immunohistochemical prognostic biomarker studies in PDAC have identified VEGF levels (Ansari et al, 2011; Smith et al, 2011), consistent with a role for the growth factor in tumour angiogenesis and hence progression and prognosis. More recently a meta-analysis assessing expression of the chemokine receptor CXCR4 supported an association between metastatic disease and overall survival in patients with PDAC (Krieg et al, 2015). Both of these prognostic biomarkers offer links to the molecular and cellular pathology of PDAC in a way that could ultimately be exploited therapeutically. As yet, however, these hopes have not been realised and there remains a need for additional prognostic biomarkers, preferably ones which may be predictive of responses to novel therapies.

Building on a previous study reporting an increase in SULF2 detected immunohistochemically in 4 of 7 patient PDAC samples relative to non-tumour tissues (Nawroth et al, 2007), the current
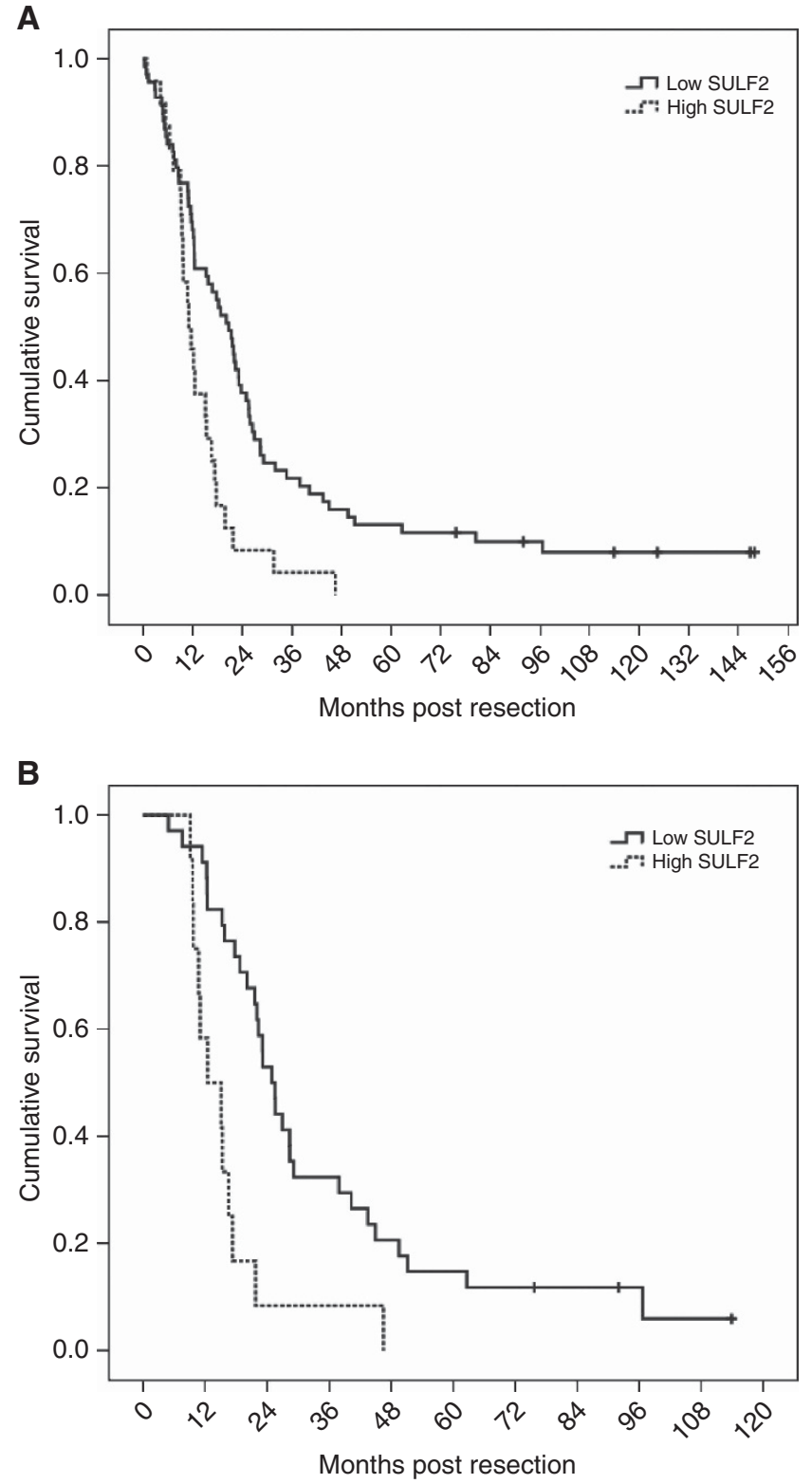

Figure 2. High SULF2 in pancreatic ductal adenocarcinoma is associated with poorer survival. Kaplan-Meier survival plots show (A) cumulative survival of patients with high SULF2 expression compared with patients with lower SULF2 expression. (B) Cumulative survival of a subset of PDAC patients receiving adjuvant chemotherapy. High SULF2 equates to cases with a percentage cells positive and SI combined score of 6-7, vs low SULF2 (scores 0-5).

study has identified expression of the extracellular endosulfatase SULF2 as poor prognostic biomarker in PDAC that is related to tumour stage, vascular invasion, radiological progression and overall survival. By controlling the degree of sulfation of extracellular HSPGs, and hence growth factor binding and signalling, SULF2 can regulate a number of growth factors that have been implicated in PDAC pathobiology, notably VEGF, Wnts and TGF- $\beta$ (Nawroth et al, 2007; Rosen and Lemjabbar-Alaoui, 2010). Importantly, SULF2 is at the interface between the PDAC cell and the tumour microenvironment, and the importance of local tumour-host cell interactions in cancer biology is increasingly recognised. Hence the biological function of SULF2, its involvement in pathways of known importance in PDAC pathogenesis and evidence that SULF2 is a prognostic biomarker, presented here, all identify this enzyme 
as a factor that has potential as both a biomarker and a therapeutic target.

Target validation data in PDAC (Nawroth et al, 2007), as well as in other tumour types (Rosen and Lemjabbar-Alaoui, 2010), are consistent with SULF2 representing a key signalling node that could be exploited therapeutically. Inhibitors of SULFs are now being described (Schelwies et al, 2010; Miller et al, 2015) and, once these have been developed to the stage where they are suitable for cell-based and preferably in vivo studies, the therapeutic potential of SULF2 inhibition can be explored. The data presented in this study is generated from a relatively small retrospective case series, which is a limitation. However, the pre-clinical data generated using molecular genetic approaches in PDAC models are compelling (Nawroth et al, 2007) and, in conjunction with the demonstration in the current study that SULF2 expression is a poor prognostic biomarker, identifies SULF2 as a priority area for further PDAC research.

\section{ACKNOWLEDGEMENTS}

HLR and this data generated in this project were supported by the Faculty of Medicine, Newcastle University and the Newcastle upon Tyne NHS Foundation Trust. SA was in part supported by a personal award from Damascus University. GB and DRN were supported by a Cancer Research UK Drug Discovery Programme Grant. Thanks also to Dr Benjamin Marrow who helped to collect clinical data.

\section{CONFLICT OF INTEREST}

The authors declare no conflict of interest.

\section{REFERENCES}

Ai X, Do AT, Lozynska O, Kusche-Gullberg M, Lindahl U, Emerson Jr. CP (2003) QSulf1 remodels the 6-O sulfation states of cell surface heparan sulfate proteoglycans to promote Wnt signaling. J Cell Biol 162(2): 341-351.

Ansari D, Rosendahl A, Elebro J, Andersson R (2011) Systematic review of immunohistochemical biomarkers to identify prognostic subgroups of patients with pancreatic cancer. Br J Surg 98(8): 1041-1055.

Apte MV, Xu Z, Pothula S, Goldstein D, Pirola RC, Wilson JS (2015) Pancreatic cancer: The microenvironment needs attention too! Pancreatology 15(4 Suppl): S32-S38.

Bilici A (2014) Prognostic factors related with survival in patients with pancreatic adenocarcinoma. World J Gastroenterol 20(31): 10802-10812.

Cancer Research UK. Cancer statistics. Available at: http:// www.cancerresearchuk.org/health-professional/cancer-statistics (accessed on November 2015).

Chrystoja CC, Diamandis EP, Brand R, Rückert F, Haun R, Molina R (2013) Pancreatic cancer. Clin Chem 59(1): 41-46.

Conroy T, Desseigne F, Ychou M, Bouche O, Guimbaud R, Becouarn Y, Adenis A, Raoul JL, Gourgou-Bourgade S, de la Fouchardiere C, Bennouna J, Bachet JB, Khemissa-Akouz F, Pere-Verge D, Delbaldo C, Assenat E, Chauffert B, Michel P, Montoto-Grillot C, Ducreux M (2011) FOLFIRINOX versus gemcitabine for metastatic pancreatic cancer. N Engl J Med 364(19): 1817-1825.

DeSantis CE, Lin CC, Mariotto AB, Siegel RL, Stein KD, Kramer JL, Alteri R, Robbins AS, Jemal A (2014) Cancer treatment and survivorship statistics, 2014. CA Cancer J Clin 64(4): 252-271.

Giovinazzo F, Turri G, Zanini S, Butturini G, Scarpa A, Bassi C (2012) Clinical implications of biological markers in pancreatic ductal adenocarcinoma. Surg Oncol 21(4): e171-e182.
Heinemann V, Boeck S (2008) Perioperative management of pancreatic cancer. Ann Oncol 19(Suppl 7): vii273-vii278.

Hur K, Han TS, Jung EJ, Yu J, Lee HJ, Kim WH, Goel A, Yang HK (2012) Up-regulated expression of sulfatases (SULF1 and SULF2) as prognostic and metastasis predictive markers in human gastric cancer. J Pathol 228(1): 88-98.

Jazieh KA, Foote MB, Diaz LA Jr (2014) The clinical utility of biomarkers in the management of pancreatic adenocarcinoma. Semin Radiat Oncol 24(2): 67-76.

Krieg A, Riemer JC, Telan LA, Gabbert HE, Knoefel WT (2015) CXCR4-a prognostic and clinicopathological biomarker for pancreatic ductal adenocarcinoma: a meta-analysis. PloS One 10(6): e0130192.

Lai JP, Sandhu DS, Yu C, Han T, Moser CD, Jackson KK, Guerrero RB, Aderca I, Isomoto H, Garrity-Park MM, Zou H, Shire AM, Nagorney DM, Sanderson SO, Adjei AA, Lee JS, Thorgeirsson SS, Roberts LR (2008) Sulfatase 2 up-regulates glypican 3 , promotes fibroblast growth factor signaling, and decreases survival in hepatocellular carcinoma. Hepatology 47(4): 1211-1222.

Lai JP, Sandhu DS, Yu C, Moser CD, Hu C, Shire AM, Aderca I, Murphy LM, Adjei AA, Sanderson S, Roberts LR (2010) Sulfatase 2 protects hepatocellular carcinoma cells against apoptosis induced by the PI3K inhibitor LY294002 and ERK and JNK kinase inhibitors. Liver Int 30(10): $1522-1528$.

Lamarca A, Feliu J (2014) Pancreatic biomarkers: could they be the answer? World J Gastroenterol 20(24): 7819-7829.

Lemjabbar-Alaoui H, van Zante A, Singer MS, Xue Q, Wang YQ, Tsay D, He B, Jablons DM, Rosen SD (2010) Sulf-2, a heparan sulfate endosulfatase, promotes human lung carcinogenesis. Oncogene 29(5): 635-646.

Lui NS, van Zante A, Rosen SD, Jablons DM, Lemjabbar-Alaoui H (2012) SULF2 expression by immunohistochemistry and overall survival in oesophageal cancer: a cohort study. BMJ Open 2. pii: e001624; e-pub ahead of print 23 November 2012; doi:10.1136/bmjopen-2012-001624.

Marengo E, Robotti E (2014) Biomarkers for pancreatic cancer: recent achievements in proteomics and genomics through classical and multivariate statistical methods. World J Gastroenterol 20(37): 13325-13342.

Miller DC, Carbain B, Beale GS, Alhasan SF, Reeves HL, Baisch U, Newell DR, Golding BT, Griffin RJ (2015) Regioselective sulfamoylation at low temperature enables concise syntheses of putative small molecule inhibitors of sulfatases. Org Biomol Chem 13(18): 5279-5284.

Morimoto-Tomita M, Uchimura K, Werb Z, Hemmerich S, Rosen SD (2002) Cloning and characterization of two extracellular heparin-degrading endosulfatases in mice and humans. J Biol Chem 277(51): 49175-49185.

Nawroth R, van Zante A, Cervantes S, McManus M, Hebrok M, Rosen SD (2007) Extracellular sulfatases, elements of the Wnt signaling pathway, positively regulate growth and tumorigenicity of human pancreatic cancer cells. PloS One 2(4): e392.

Phillips JJ, Huillard E, Robinson AE, Ward A, Lum DH, Polley MY, Rosen SD, Rowitch DH, Werb Z (2012) Heparan sulfate sulfatase SULF2 regulates PDGFRalpha signaling and growth in human and mouse malignant glioma. J Clin Invest 122(3): 911-922.

Pye DA, Vives RR, Hyde P, Gallagher JT (2000) Regulation of FGF-1 mitogenic activity by heparan sulfate oligosaccharides is dependent on specific structural features: differential requirements for the modulation of FGF-1 and FGF-2. Glycobiology 10(11): 1183-1192.

Pye DA, Vives RR, Turnbull JE, Hyde P, Gallagher JT (1998) Heparan sulfate oligosaccharides require 6-O-sulfation for promotion of basic fibroblast growth factor mitogenic activity. J Biol Chem 273(36): 22936-22942.

Rosen SD, Lemjabbar-Alaoui H (2010) Sulf-2: an extracellular modulator of cell signaling and a cancer target candidate. Expert Opin Ther Targets 14(9): 935-949.

Saad OM, Ebel H, Uchimura K, Rosen SD, Bertozzi CR, Leary JA (2005) Compositional profiling of heparin/heparan sulfate using mass spectrometry: assay for specificity of a novel extracellular human endosulfatase. Glycobiology 15(8): 818-826.

Schelwies M, Brinson D, Otsuki S, Hong YH, Lotz MK, Wong CH, Hanson SR (2010) Glucosamine-6-sulfamate analogues of heparan sulfate as inhibitors of endosulfatases. Chembiochem 11(17): 2393-2397.

Seo Y, Baba H, Fukuda T, Takashima M, Sugimachi K (2000) High expression of vascular endothelial growth factor is associated with liver metastasis and a poor prognosis for patients with ductal pancreatic adenocarcinoma. Cancer 88(10): 2239-2245. 
Siegel R, Naishadham D, Jemal A (2012) Cancer statistics, 2012. CA Cancer J Clin 62(1): 10-29.

Smith RA, Tang J, Tudur-Smith C, Neoptolemos JP, Ghaneh P (2011) Meta-analysis of immunohistochemical prognostic markers in resected pancreatic cancer. Br J Cancer 104(9): 1440-1451.

Staples GO, Shi X, Zaia J (2011) Glycomics analysis of mammalian heparan sulfates modified by the human extracellular sulfatase HSulf2. PloS One 6(2): e16689.

Thota R, Pauff JM, Berlin JD (2014) Treatment of metastatic pancreatic adenocarcinoma: a review. Oncology 28(1): 70-74.

Waddell N, Pajic M, Patch AM, Chang DK, Kassahn KS, Bailey P, Johns AL, Miller D, Nones K, Quek K, Quinn MC, Robertson AJ, Fadlullah MZ, Bruxner TJ, Christ AN, Harliwong I, Idrisoglu S, Manning S, Nourse C, Nourbakhsh E, Wani S, Wilson PJ, Markham E, Cloonan N, Anderson MJ, Fink JL, Holmes O, Kazakoff SH, Leonard C, Newell F, Poudel B, Song S, Taylor D, Waddell N, Wood S, Xu Q, Wu J, Pinese M, Cowley MJ, Lee HC, Jones MD, Nagrial AM, Humphris J, Chantrill LA, Chin V, Steinmann AM, Mawson A, Humphrey ES, Colvin EK, Chou A,
Scarlett CJ, Pinho AV, Giry-Laterriere M, Rooman I, Samra JS, Kench JG, Pettitt JA, Merrett ND, Toon C, Epari K, Nguyen NQ, Barbour A, Zeps N, Jamieson NB, Graham JS, Niclou SP, Bjerkvig R, Grutzmann R, Aust D, Hruban RH, Maitra A, Iacobuzio-Donahue CA, Wolfgang CL, Morgan RA, Lawlor RT, Corbo V, Bassi C, Falconi M, Zamboni G, Tortora G,

Tempero MA. Australian Pancreatic Cancer Genome IGill AJ, Eshleman JR, Pilarsky C, Scarpa A, Musgrove EA, Pearson JV, Biankin AV, Grimmond SM (2015) Whole genomes redefine the mutational landscape of pancreatic cancer. Nature 518(7540): 495-501.

Winter JM, Yeo CJ, Brody JR (2013) Diagnostic, prognostic, and predictive biomarkers in pancreatic cancer. J Surg Oncol 107(1): 15-22.

This work is published under the standard license to publish agreement. After 12 months the work will become freely available and the license terms will switch to a Creative Commons AttributionNonCommercial-Share Alike 4.0 Unported License.

Supplementary Information accompanies this paper on British Journal of Cancer website (http://www.nature.com/bjc) 